\title{
Impacto da Convergência às Normas Contábeis Internacionais no Brasil Sobre o Conteúdo Informacional da Contabilidade
}

\begin{abstract}
Resumo
Este artigo tem como objetivo analisar o impacto do processo de convergência às normas contábeis internacionais no Brasil sobre o conteúdo informacional da Contabilidade, tendo como foco alterações nos principais índices contábil-financeiros e na relevância das informações contábeis. Para tanto, foram analisadas empresas não financeiras de capital aberto, considerando informações do exercício de 2009 divulgadas no início de 2010 (BRGAAP - padrão parcialmente IFRS) e no início de 2011 (full IFRS). A análise de dados do exercício de 2009 teve como propósito isolar toda e qualquer outra influência encontrada nas demonstrações contábeis que não fosse proveniente das alterações de padrão contábil. Os resultados apontaram que os indicadores Endividamento (END), Giro do Ativo (GA), Margem Bruta (MB), Fluxo de Caixa Operacional sobre Ativo Total (FSA) e Fluxo de Caixa Operacional sobre Patrimônio Líquido (FSPL) mostraram-se menores, quando utilizados dados das demonstrações em full IFRS. Analisado a capacidade informacional do Lucro Líquido, por meio de regressão, foi possível detectar que, ao refletir o padrão full IFRS, o Lucro Líquido aumenta seu poder explicativo sobre o comportamento dos preços das ações. Em relação ao conteúdo informacional do Patrimônio Líquido, os resultados apontaram que não houve alteração significativa no seu poder explicativo do comportamento dos preços das ações.
\end{abstract}

Palavras-chave: IFRS. Conteúdo Informacional da Contabilidade. Processo de Convergência às Normas Internacionais de Contabilidade. Índices Contábeis.

\begin{abstract}
Marcelo Alvaro da Silva Macedo Doutor em Engenharia de Produção (COPPE/UFRJ) e Pós-Doutorado em Controladoria e Contabilidade (USP), Professor Adjunto da Universidade Federal do Rio de Janeiro (UFRJ). Contato: Av. Pasteur, 250, LEDO/FACC/UFRJ - Sala 250, Urca, Rio de Janeiro, RJ, CEP 22.290-940. E-mail: malvaro.facc.ufrj@gmail.com
\end{abstract}

\section{Márcia Reis Machado}

Doutora em Contabilidade (USP), Professora da Universidade Federal da Paraíba (UFPB). Contato: UFPB, CCSA, Campus I, Cidade Universitária, Castelo Branco, João Pessoa, PB, CEP 58059-900. E-mail: marciareism@hotmail.com

Márcio André Veras Machado Doutor em Administração (UNB), Professora da Universidade Federal da Paraíba (UFPB). Contato: UFPB, CCSA, Campus I, Cidade Universitária, Castelo Branco, João Pessoa, PB, CEP 58059-900. E-mail: mavmachado@hotmail.com

\section{Pedro Henrique Cardoso} Mendonça Graduado em Ciências Contábeis (UFRJ). Contato: Av. Pasteur, 250, LED0/FACC/ UFRJ - Sala 250, Urca, Rio de Janeiro, RJ, CEP 22.290-940.

E-mail: phcardoso.m@gmail.com 


\section{Introdução}

O surgimento e desenvolvimento de empresas multinacionais, o crescimento do mercado financeiro internacional e a mudança do comportamento dos investidores que, entre outros fatores, contribuiu para a internacionalização da atividade econômica, fez com que os relatórios contábeis ultrapassem as fronteiras nacionais. No entanto, a interpretação e a compreensão da informação contábil, em nível internacional são prejudicadas por uma multiplicidade de fatores, incluindo a diversidade dos princípios contábeis e regras que regem a elaboração de relatórios contábil-financeiros em cada país (Callao, Jarne \& Laínez, 2007).

À medida que foram aparecendo, como consequência da evolução dos tempos e das organizações, os outros "players", a Contabilidade foi se transformando, aos poucos, de um engenhoso sistema de escrituração e demonstrações contábeis simplificadas, num complexo sistema de informação e avaliação, com características científicas, institucionais e sociais de relevo e tendo, como objetivo central, suprir necessidade informacional de seus usuários internos e externos à entidade a que se refere (Iudícibus, Martins \& Carvalho, 2005, p.11).

A Estrutura Conceitual para Elaboração e Divulgação de Relatório Contábil-Financeiro, anteriormente denominada Estrutura Conceitual Básica da Contabilidade, não trata mais dos objetivos da Contabilidade, mas dos objetivos do relatório contábil-financeiro. Possivelmente, essa mudança decorre da constante evolução da economia e, consequentemente, da ampliação das tarefas realizadas pela Contabilidade.

Segundo o Comitê de Pronunciamentos Contábeis - CPC (2011), o objetivo do relatório contábil-financeiro é fornecer informações contábil-financeiras que sejam úteis a investidores existentes e em potencial, a credores por empréstimos e a investidores. Enfatiza, ainda, que os relatórios contábil-financeiros podem não atender a todas as informações que os usuários (investidores e credores) necessitam, cabendo, assim, aos usuários, buscar outras fontes de informações, tais como: condições econômicas, situação política, e perspectiva e panorama para a indústria e para a entidade.

$\mathrm{Na}$ atual conjuntura, é notória a evolução do mercado de capitais brasileiro, até mesmo em momentos em que Estados Unidos e Europa passam por crise econômica. Mesmo considerado incipiente, em relação a mercados como o americano, o volume negociado na bolsa e o número de investidores tem crescido rapidamente. Segundo as estatísticas disponíveis no site da Bolsa de Mercadorias, Valores e Futuros (BM\&FBOVESPA), em 2002, eram 85.249 investidores pessoa física. Em fevereiros de 2012, esse número pulou para 569.826.

Nesse contexto, percebe-se a necessidade de Contabilidade com linguagem universal, que acompanhe a necessidade informacional dos investidores e credores em um mercado sem fronteiras e cada vez mais complexo. Enfatizam Carvalho, Lemes e Costa (2008, p. 14) que "não há mercados de capitais fortes sem transparência e sem divulgação, e o mecanismo por excelência da transparência e da divulgação nesses mercados é o do conjunto das demonstrações ditas financeiras ou contábeis". Corroborando esse pensamento, o CPC ressalta a necessidade de utilizar-se de informações além das apresentadas nos demonstrativos contábil-financeiros.

Para sanar as barreiras da linguagem contábil, mais de 100 países estão engajados no desafio de seguir um padrão comum de práticas contábeis. Para tanto, estão adotando as normas internacionais emitidas pelo International Accounting Standards Board (IASB). No Brasil, esse processo de convergência às normas internacionais de contabilidade teve início com a Lei $\mathrm{n}^{\circ}$ 11.638, de 28 de dezembro de 2007, vigente a partir de janeiro de 2008. Durante esse processo de mudanças, foram observadas modificações conceituais, mudanças de critério contábil, mudanças de classificação e contabilização de operações, até então apresentadas fora do balanço. Salienta-se que o processo de internacionalização da contabilidade, que ocasionou nas referidas mudanças, conforme Lantoo e Sahlströn (2009) tem por fim melhorar a transparência e a comparabilidade das demonstrações contábeis.

Considerando essas mudanças, este artigo apresenta o seguinte problema de pesquisa: qual o impacto do processo de convergência às normas contábeis internacionais no Brasil sobre o conteúdo informacional da Contabilidade? 
Em decorrência do problema levantado, o presente estudo tem por objetivo analisar o impacto do processo de convergência às normas contábeis internacionais no Brasil sobre o conteúdo informacional da Contabilidade, tendo como base duas perspectivas: mudanças causadas nos principais índices contábil-financeiros e alterações no poder explicativo das informações contábeis Lucro Líquido (LL) e Patrimônio Líquido (PL) sobre o preço das ações no mercado brasileiro de capitais.

Para atingir o objetivo proposto, foi necessário seu desmembramento em dois objetivos específicos: (i) verificar se existem indícios de diferença significativa entre os índices calculados para as informações de 2009 publicadas em 2010 e para as reapresentadas em 2011; (ii) verificar se existem indícios de mudança no poder explicativo do preço das ações das empresas no mercado brasileiro de capitais, quando do uso das informações de 2009 publicadas em 2010 e as reapresentadas em 2011.

\section{Revisão da Literatura}

\subsection{O Processo de Internacionalização da Contabilidade}

O processo de internacionalização da Contabilidade é o processo pelo qual vários países, em comum acordo, realizam mudanças em seus sistemas contábeis, reduzindo as divergências contábeis entre os países e tornando-as compatíveis (Weffort, 2005). Esse processo não pode ser considerado como uma padronização de normas contábeis, mas uma harmonização. Segundo Niyama (2006), a padronização é um processo de uniformização de critérios, não admitindo flexibilidade; enquanto a harmonização preserva as particularidades inerentes a cada país.

Segundo Santos e Calixto (2010), o a adoção das IFRS no Brasil, tal como ocorre em outros países, trará para as empresas benefícios de liquidez, menor custo de capital e maior valorização e atratividade no mercado. Em empresas multinacionais, a harmonização reduz os custos para gerenciar sistemas contábeis diferenciados (de acordo com cada país) e também facilita a tarefa de elaboração das demonstrações consolidas, além de reduzir a perda informacional na conversão de padrões contábeis.

Por outro lado, uma Contabilidade mais calcada em julgamentos pode contribuir para um ambiente mais propício à prática da manipulação de resultados, sendo as taxas de descontos utilizadas para trazer a valores presentes direitos e obrigações de longo prazo e as taxas de depreciação baseadas na vida útil dos ativos exemplos potenciais de instrumentos de gerenciamento. Ressalta-se que utilizar o julgamento na prática contábil não caracteriza utilização de gerenciamento de resultado (Baptista, 2009).

No Brasil, em decorrência da herança do direito romano ou code law, as leis determinam as normas contábeis propriamente ditas e quais órgãos governamentais têm o poder para tratar das referidas normas. Desse modo, as normas provêm dos textos legais, consequentemente, leis e decretos tendem a ser a base normativa para a prática contábil. Nesse contexto, o estabelecimento de normas e padrões contábeis foi praticado, em quase sua totalidade, pelo governo, resultando em forte vinculação entre os aspectos contábeis e tributários (Iudícibus, 2010).

Além do sistema legal brasileiro, que influencia a prática contábil, o fato do mercado de capitais brasileiro, se comparado a mercados internacionais, ser menos desenvolvido também impacta fortemente a qualidade e a relevância das informações contábeis evidenciadas.

Em empresas com poucos acionistas (no caso brasileiro, em muitas empresas o controle acionário está nas mãos de um único acionista), a Contabilidade perde o seu papel de redutora de assimetria de informação entre acionistas e gestores. Nessas empresas, o acionista majoritário possui acesso privilegiado às informações gerenciais da empresa, não necessitando da Contabilidade para orientar suas decisões de investimento. (Lopes, 2002, p.77). 
Lantoo e Sahlströn (2009) destacam que estudos anteriores demonstram que a adoção das IFRS melhorar a transparência e comparabilidade das demonstrações financeiras entre as empresas. No geral, a adoção do IFRS beneficia os investidores, especialmente em países em que os investidores, existentes e em potencial, não têm sido prioridade de órgão normatizadores, a exemplo do Brasil e de muitos países da Europa. Observa-se essa mudança de prioridade, quando o Pronunciamento Conceitual Básico (R1), correlacionado às Normas Internacionais de Contabilidade (IASB) - BV 2011 Blue Book., estabelece que o objetivo dos relatórios contábeis-financeiros é fornecer informações que sejam úteis para a toda de decisão ligada ao fornecimento de recursos da entidade, considerando, por tanto, como usuários primários da contabilidade investidores existentes e em potencial, credores por empréstimos e outros credores.

\subsection{O Processo de Convergência no Brasil}

O processo de convergência no Brasil foi marcado por dois acontecimentos: a criação do Comitê de Pronunciamentos Contábeis (CPC), pela Resolução $n^{\circ} 1.055$ (2005) e a promulgação da Lei ${ }^{\circ} 11.638$ (2007). Porém, é necessário destacar alguns antecedentes, tais como o Comunicado do Banco Central (BACEN) no 14.259/06 (2006), a Instrução da Comissão de Valores Mobiliários (CVM) nº 457/07 (2007) e a Circular da Superintendência de Seguros Privados (SUSEP) no 357/07 (2007). Em todos os casos, foram tratados de aspectos específicos para divulgação de informações no padrão IFRS.

Aos moldes do International Accounting Syandards Board (IASB), o CPC é formado por quem prepara as informações (contadores e empresas), quem audita essas informações, quem as analisam, os intermediários financeiros e a academia, na figura dos seguintes órgãos: Conselho Federal de Contabilidade (CFC), Associação Brasileiras das Companhias Abertas (ABRASCA), Instituto dos Auditores Independentes do Brasil (IBRACON), Associação dos Analistas e Profissionais de Investimentos do Mercado de Capitais (APIMEC), Bolsa de Mercadorias, Valores e Futuros (BM\&FBOVESPA); e Fundação Instituto de Pesquisa Contábeis, Atuariais e Financeiras (FIPECAFI).

O segundo acontecimento, divisor de águas nesse processo de convergência, foi a promulgação da Lei ${ }^{\circ} 11.638 / 07$ (2007), que promoveu uma série de mudanças nas práticas contábeis e determinou, em seu Art. 177, $₫ 5^{\circ}$, que as normas expedidas pela Comissão de Valores Mobiliários (CVM) sejam elaboradas em consonância com os padrões internacionais de Contabilidade. Destaca-se que a referida Lei foi fruto do Projeto de Lei n ${ }^{\circ} 3.741$, entregue à Câmara dos Deputados, em 2000, propondo a modificação do capítulo da Lei $n^{\circ} 6.404 / 76$, que trata de assuntos contábeis, com o intuito de eliminar as barreiras regulatórias e alinhar as normas e práticas contábeis brasileiras às internacionais.

O CPC foi criado com o objetivo de estudar, preparar e emitir Pronunciamentos Técnicos sobre procedimentos de Contabilidade e a divulgação de informações dessa natureza, em função da necessidade da convergência internacional das normas contábeis, da necessidade de centralizar a emissão de normas dessa natureza no Brasil e da necessidade de que as normas sejam elaboradas sob um processo democrático. No entanto, o referido órgão não tem poderes legais para emitir normas de Contabilidade, porque a Constituição brasileira impede que órgãos governamentais deleguem funções a outras entidades (Iudícibus, Martins, Gelbcke \& Santos, 2010) Diante desse fator limitante, ficou acordado que o CPC, primeiramente, emite os Pronunciamentos Técnicos e, em seguida, os órgãos com competência para normatizar (CFC, CVM, Banco Central e Agências Reguladoras) emitem suas próprias resoluções acatando e determinado o seguimento dos Pronunciamentos do CPC. Até março de 2012, o CPC já havia emitido 39 Pronunciamentos Técnicos, dos quais todos foram aprovados pela CVM e CFC, 38 pela Agência Nacional de Saúde (ANS), 36 pela SUSEP, 19 pela Agência Nacional de Energia Elétrica (ANEEL), sete pelo Banco Central e quatro pela Agência Nacional de Transportes Terrestres (ANTT), além do Pronunciamento Conceitual Básico e o Pronunciamento para Pequenas e Médias Empresas. 
Destaca-se que o CPC tem a missão de tratar de uma dupla convergência:

de um lado a necessidade universal de integrar regras contábeis aos padrões internacionais; de outro, a participação, no debate interno, de representantes de todos os atores do mercado brasileiro - governo, iniciativa privada e órgãos acadêmicos - dialogando livre e democraticamente no CPC. (Plöger, 2005).

Complementando as mudanças iniciadas pela Lei ${ }^{\circ} 11.638 / 07$ (2007) às práticas contábeis, a Lei $\mathrm{n}^{\circ}$ 11.941/09 (2009), dentre várias alterações trazidas a Lei das Sociedades por Ações, foi taxativa, ao determinar, em seu Art. 177, $₫ 2$, que a escrituração mercantil e as demonstrações reguladas pela referida lei não podem ser modificadas em função de lei tributária ou legislação específica.

Durante o processo de convergência, com alteração da Lei $n^{\circ}$ 6.404/76 (1976) - Lei das Sociedades por Ações e emissão dos Pronunciamentos Técnicos do CPC, observou-se diversas mudanças na prática contábil, as quais podem ser classificadas em: (i) mudanças de critérios contábeis; (ii) mudanças de classificação; e (iii) contabilização de operações apresentadas fora do balanço. De modo resumido, apresentam-se, no Apêndice 1, algumas das principais mudanças, especialmente, as que podem ter ocasionado efeitos significativos nas demonstrações contábil-financeiras.

\subsection{Evidências Empíricas}

Com o avanço do processo de convergência às normas internacionais, diversas pesquisas têm sido desenvolvidas, especialmente com o intuito de verificar a influência da adoção das IFRS na qualidade da informação contábil. A seguir, apresentam-se, resumidamente, alguns dos estudos que de alguma forma trataram do processo de convergência.

Bartov, Goldberg e Kim (2005), utilizando dados de 417 empresas alemãs, observaram maior relevância das informações contábeis em US-GAAP e IFRS, quando comparado com o padrão contábil alemão. Barth, Landsman e Lang (2008), por meio de uma pesquisa em 21 países, também observaram que a relevância das informações com padrão internacional era maior do que com a adoção de padrões locais. Corroborando, Morais e Curto (2009) mostram que, nos países Europeus, as informações em IFRS são mais relevantes que as informações em GAAPs locais.

O estudo realizado por Perramon e Amat (2006) indicou que a adoção das normas internacionais de Contabilidade pode influenciar no resultado de empresas espanholas de diferentes tamanhos e rentabilidade. Já Hung e Subramanyam (2007) concluíram que o ativo total e o patrimônio líquido, bem como as variações no lucro e no patrimônio líquido, foram mais relevantes pelo padrão internacional do que pelo padrão alemão. Nessa mesma linha de pesquisa, Chalmers, Clinch e Godfrey (2009) indicam que os valores dos lucros de empresas australianas tornaram-se mais relevantes com a adoção do IFRS, mas o valor do patrimônio não se alterou significativamente. Por outro lado, Haller, Ernstberger e Froschhammer (2009) analisaram de 103 empresas alemãs e constataram um aumento do patrimônio e do lucro líquido após a adoção do IFRS em 2005.

Chalmers, Clinch e Godfrey (2008) concluíram que a acurácia das previsões dos analistas financeiros se elevou após a implantação dos padrões internacionais de Contabilidade, indicando melhoria de qualidade das informações disponíveis aos analistas. Analisando indicadores financeiros, Miranda (2008) concluiu que a adoção das normas IFRS pode provocar mudanças significativas em indicadores econômico-financeiros de bancos de alguns países europeus. Lantto e Sahlström (2009), em estudo de empresas finladesas, encontraram uma mudança positiva de magnitude dos principais índices contábeis após a adoção do IFRS. Já Silva, Couto e Cordeiro (2009) indicaram que houve um impacto significativo, de maneira geral aumentos, nas informações dos relatórios financeiros de empresas portuguesas de capital aberto ao se adotar o IFRS. 
Ding, Hope, Jeanjean, e Stolowy (2007) demonstraram, com uma amostra de 30 países, com dados de 2001, que o índice ausência (extensão em que as regras sobre determinadas questões contábeis estão faltando nos padrões nacionais) é determinado, dentre outros elementos, pela importância do mercado de ações e concentração de propriedade. Já o indicador de divergência (extensão em que as regras relativas à mesma questão contábil diferem em padrões nacionais e internacionais) está positivamente associada com o nível de desenvolvimento econômico e da importância da profissão contábil, mas é limitado pela importância dos mercados de ações. Destacaram, ainda, que um maior nível de ausência implica mais oportunidades para gerenciamento de resultados e para diminuição de informações específicas para os investidores. Enquanto que a maior divergência do IAS está associada a informações mais ricas nos mercados de capitais.

No contexto nacional, Santos e Calixto (2010) pesquisaram os efeitos da primeira fase de transição do IFRS nas empresas listadas no Bovespa, a partir de 2008, e encontraram resultados (lucro) superiores com o IFRS do que com a norma anterior, o que pode ser explicado pela redução do conservadorismo contábil brasileiro. Lima (2010) constatou que os ajustes de reconciliação do lucro líquido e do patrimônio líquido no período de transição entre o padrão contábil brasileiro e as normas IFRS, foram relevantes para o mercado brasileiro de capitais.

Macedo, Machado e Machado (2011) observaram diferenças na relevância da informação contábil de LLPA e PLPA, nos períodos pré e pós primeira fase do processo de convergência às normas internacionais de Contabilidade no Brasil, com o LLPA apresentando um ganho e o PLPA uma perda de conteúdo informacional. O estudo de Braga, Araujo, Macedo e Corrar (2011) mostrou que houve mudança significativa (aumento) apenas no índice de endividamento com a reapresentação das demonstrações contábeis referentes ao exercício de 2007, de acordo com as novas práticas contábeis adotadas no Brasil.

De maneira geral, os trabalhos relatados até este ponto, mostram impactos positivos da adoção do IFRS. Porém, alguns estudos não corroboram esses resultados. O estudo de Niskaen, Kinnunen e Kasanen (2000), para empresas na Finlândia, mostra que a mudança nos lucros do padrão local para o IFRS não trouxe incremento significativo de relevância para essa informação contábil. Nessa mesma linha, Van der Meulen, Gaeremynck e Willekens (2007) mostram não existir diferença significativa de relevância entre o lucro apresentado em US-GAAP e em IFRS para empresas do German New Market. Já o trabalho de Vishnani e Shah (2008) mostra que as novas informações trazidas pela DFC, por conta do processo de convergência às normas internacionais na Índia, não são relevantes.

No Brasil, Grecco, Geron e Formigoni (2009) mostraram que a adoção das novas práticas contábeis em 2008 trouxe um maior nível de conservadorismo às demonstrações contábeis das companhias abertas brasileiras. Por fim, Klann e Beuren (2011) concluíram que, embora se esperasse uma qualidade maior com a adoção das normas do IASB, a aplicação do IFRS em alguns países não correspondeu à expectativa, ao não apresentar diferenças significativas em relação ao padrão local, no que diz respeito ao gerenciamento dos resultados.

É nesse contexto que se insere o presente estudo, pretendendo analisar o impacto da adoção das IFRS no Brasil, sob duas perspectivas: das mudanças nas informações contábeis, com a análise de indicadores financeiros construídos com informações em BRGAAP e em IFRS; e da relevância da informação contábil, procurando analisar qual informação contábil é capaz de explicar melhor o preço das ações: se a informação em BRGAAP ou se a informação em IFRS.

Nessa mesma linha pode-se destacar os estudos de Perramon e Amat (2006); Silva, Couto e Cordeiro (2009); Haller, Ernstberger e Froschhammer (2009); Lantto e Sahlström (2009); Santos e Calixto (2010) e Braga et al. (2011), que estudaram o impacto da adoção das IFRS pela análise das mudanças nas informações contábeis. Já os estudos de Niskaen, Kinnunen e Kasanen (2000); Bartov, Goldberg e Kim (2005); Van der Meulen, Gaeremynck e Willekens (2007); Hung e Subramanyam (2007); Morais e Curto (2008); Barth, Landsman e Lang (2008); Morais e Curto (2009); Chalmers, Clinch e Godfrey (2009) e Macedo, Machado e Machado (2011), analisaram a questão sob a perspectiva da relevância da informação contábil para o mercado de capitais. 


\section{Metodologia}

Essa pesquisa pode ser caracterizada, de acordo com Vergara (2010), como um estudo descritivo e explicativo, pois procura expor o impacto da adoção do IFRS no conteúdo informacional da Contabilidade, por meio da análise das diferenças em indicadores contábil-financeiros e da análise da relação entre essas informações e o comportamento dos preços das ações. Quanto à abordagem utilizada, classifica-se, de acordo com Martins e Theóphilo (2009), como empírico-positivista, pois apresenta técnicas de coleta, tratamento e análise de dados marcadamente quantitativos e onde a validação da prova científica é buscada através de testes dos instrumentos, graus de significância e sistematização das definições operacionais.

O processo de amostragem é não probabilístico, pois parte-se de um universo naturalmente restrito, já que as empresas foram escolhidas a partir da listagem das empresas não financeiras de capital de aberto da base de dados da Economática. As empresas incluídas no estudo foram aquelas que apresentaram as informações necessárias em cada ano da análise. Como parte da análise depende da relação entre preço das ações e as informações contábeis, utilizou-se um critério de corte pela liquidez das ações, considerando o valor de 0,01 como mínimo para que a empresas pudesse ser incluída na análise. Esse critério se torna importante em estudos desta natureza para que se considerem empresas que possam ter seus preços refletindo as informações relevantes disponíveis no mercado (hipótese de eficiência semi-forte de mercado). Com isso, a amostra final ficou composta por 148 empresas.

Foram coletadas da Economática informações referentes ao Lucro Líquido por ação (LLPA), ao Patrimônio Líquido por ação (PLPA), Lucro Líquido (LL), Patrimônio Líquido (PL), Ativo Total (AT), Ativo Circulante (AC), Ativo Realizável a Longo Prazo (RLP), Passivo Circulante (PC), Passivo Exigível a Longo Prazo (ELP), Receita Líquida (RL), Lucro Bruto (LB) e Fluxo de Caixa Operacional (FCO). Cabe ressaltar que foram mantidas as nomenclaturas utilizadas pela Economática.

Com base nessas informações, foi possível calcular os indicadores utilizados na análise. A escolha dos indicadores foi feita por julgamento dos autores, com base nos principais indicadores abordados em obras tais como Assaf Neto (2006), Braga (2003), Iudícibus (2008), Marques, Carneiro Junior e Kühl (2008), Matarazzo (2003), Pereira da Silva (2008) e Perez Jr. e Begalli (2002). Os indicadores calculados e considerados na análise estão apresentados na Figura 1.

Um ponto que merece destaque é que para esta parte da análise procurou-se considerar indicadores contábil-financeiros das mais diversas perspectivas. Por conta disso, percebe-se a existência de dois indicadores de estrutura de capital, dois de liquidez, um de giro, dois de margem, dois de rentabilidade e dois de fluxo de caixa.

\begin{tabular}{lcc}
\hline \multicolumn{1}{c}{ Denominação } & Sigla & Fórmula \\
\hline Participação de Capital de Terceiros & $\mathrm{PCT}$ & (PC+ELP)/AT \\
\hline Endividamento & $\mathrm{END}$ & (PC+ELP)/PL \\
\hline Liquidez Geral & $\mathrm{LG}$ & $(\mathrm{AC}+\mathrm{RLP}) /(\mathrm{PC}+\mathrm{ELP})$ \\
\hline Liquidez Corrente & $\mathrm{LC}$ & $\mathrm{AC} / \mathrm{PC}$ \\
\hline Giro do Ativo & $\mathrm{GA}$ & $\mathrm{RL} / \mathrm{AT}$ \\
\hline Margem Bruta & $\mathrm{MB}$ & $\mathrm{LB} / \mathrm{RL}$ \\
\hline Margem Líquida & $\mathrm{ML}$ & $\mathrm{LL} / \mathrm{RL}$ \\
\hline Retorno sobre o Ativo & $\mathrm{RSA}$ & $\mathrm{LL} / \mathrm{AT}$ \\
\hline Retorno sobre o Patrimônio Líquido & $\mathrm{RSPL}$ & $\mathrm{LL} / \mathrm{PL}$ \\
\hline Fluxo de Caixa Operacional sobre Ativo Total & $\mathrm{FSA}$ & $\mathrm{FCO/AT}$ \\
\hline Fluxo de Caixa Operacional sobre o Patrimônio Líquido & $\mathrm{FSPL}$ & $\mathrm{FCO/PL}$ \\
\hline
\end{tabular}

Figura 1. Indicadores Contábil-Financeiros Analisados

Fonte: Dados da Pesquisa 
Além disso, para análise da relevância das informações contábeis para o mercado de capitais, foi coletado o preço da ação de maior liquidez de cada empresa, considerando o índice de negociabilidade disponibilizado pelo Economática. Os preços coletados foram os de fechamento para o dia 30/04/2010. A utilização da data limite de divulgação das demonstrações contábil-financeiras, assumindo certa eficiência no mercado brasileiro de capitais, tem como justificativa o fato de considerar que o impacto dessas informações já estaria incorporado no preço das ações das empresas.

Esse artifício de considerar apenas uma única data para os preços e não a data de publicação das demonstrações de cada empresa segue as orientações de outros estudos que também utilizaram essa mesma simplificação, tais como os de Lang, Raedy e Yetman (2003), Costa e Lopes (2007) e Morais e Curto (2008).

A escolha do exercício de 2009 para esta análise é justificada pelo fato de que, para esse exercício, teve-se a mesma informação em dois GAAPs (Generally Accepted Accounting Principles): BRGAAP (padrão local brasileiro) e o IFRS (International Financial Reporting Standards). Isso porque, no Brasil, a obrigatoriedade de aplicação do padrão full IFRS se deu apenas para o exercício de 2010 e as empresas, para tornar as informações de 2009 comparáveis com as de 2010, foram obrigadas a reapresentar as mesmas em 2011 junto com as demonstrações contábil-financeiras de 2010.

Na primeira parte da análise, a lógica consiste em analisar as diferenças existentes entre indicadores calculados com dados de 2009 publicados em 2010 e com os reapresentados em 2011.

Para tanto, foi testado se as informações de cada índice calculado eram provenientes de uma mesma população. Caso isso fosse confirmado por teste de igualdade de médias, significaria que não haveria diferença estatisticamente significativa entre os valores de cada indicador em cada um dos padrões contábeis considerados. Operacionalmente, testou-se se a média de cada índice calculado para os dados de 2009 publicados em 2010 (BRGAAP) é igual à média do índice calculado para os dados de 2009 reapresentados em 2011, ou seja, $H_{0}$ : indicador (2009-2010) - indicador (2009-2011) = 0. Logo, $H_{1}$ : indicador (2009-2010) - indicador (2009-2011) $\neq 0$.

Como as informações que estão sendo analisadas são de um mesmo conjunto de empresas em duas situações diferentes, ou seja, procura-se analisar as mesmas informações apresentadas em dois GAAPs diferentes, justifica-se a aplicação de testes de diferenças de médias para duas amostras emparelhadas.

Segundo Siegel e Castellan Jr. (2006), os testes para amostras emparelhadas são aplicados quando o pesquisador deseja estabelecer se dois tratamentos são diferentes. No caso das demonstrações do ano de 2009, deseja-se testar se o tratamento dado à informação contábil pelo padrão local brasileiro (BRGAAP) é diferente do tratamento dado pelo padrão internacional (IFRS), ou seja, se a adoção dos IFRS geram impacto significativo no conteúdo informacional da Contabilidade, no caso específico dos indicadores sob análise.

A escolha do teste para amostras emparelhadas dependerá da avaliação do pressuposto básico de que as variáveis (indicadores) tenham distribuição normal. Para testar o referido pressuposto, foi utilizado o teste de "Komolgorov-Smirnov", tendo como referência um nível de significância de 5\%. Como mostrado na análise dos dados, os indicadores contábil-financeiros não apresentaram distribuição normal. Nesse caso, foram utilizados os dois testes não paramétricos mais indicados para o caso de duas amostras emparelhadas: teste não paramétrico dos Sinais e teste não paramétrico de Wilcoxon.

No caso do presente estudo, para os testes dos Sinais e do Wilcoxon, a aceitação de $\mathrm{H}_{0}$ mostra indícios de que os indicadores com base nas informações de 2009 publicadas em 2010 ou reapresentadas em 2011 são iguais. No caso de rejeição de $\mathrm{H}_{0}$, os indícios são de que existam diferenças significativas entre os indicadores calculados a partir dos dois formatos de informações contábeis.

$\mathrm{Na}$ segunda parte da análise, o objetivo ainda está relacionado à análise do impacto da adoção do IFRS no conteúdo informacional das demonstrações contábil-financeiras, porém o foco da análise é substancialmente diferente do anterior. Nesse caso, o foco é analisar se a adoção do padrão full IFRS altera a capacidade de explicação do preço das ações das empresas no mercado brasileiro de capitais pelas informações contábeis de LLPA e PLPA. Essa análise é conduzida por meio da aplicação da análise de regressão. 
A análise está dividida em duas partes, sendo a primeira utilizando-se apenas o lucro líquido (LLPA) e a segunda apenas o patrimônio líquido (PLPA). Para todas as análises, fez-se uso de regressões lineares simples em cross-section, tendo sempre o preço como variável dependente e as informações contábeis, individualmente, como variáveis independentes. Ressalta-se que o foco da análise do presente estudo, como dito anteriormente, está na discussão sobre qual informação de 2009 é capaz de mais acuradamente explicar o comportamento do preço das ações das empresas no mercado brasileiro de capitais, se a informação publicada em 2010 ou se aquela reapresentada em 2011.

Assim, para verificar individualmente a capacidade explicativa das informações contábeis de LLPA e PLPA, ou seja, a relação existente entre o preço das ações e as informações contábeis, utilizou-se as seguintes equações, com base nos estudos de Collins, Maydew e Weiss (1997) e Macedo, Machado, Murcia e Machado. (2011):

$$
\begin{aligned}
& \mathrm{p}_{i, t}=\alpha_{0}+\alpha_{1} L L P A_{i, t}+\varepsilon_{i} \\
& \mathrm{p}_{i, t}=\alpha_{0}+\alpha_{1} P L P A_{i, t}+\varepsilon_{i}
\end{aligned}
$$

Onde:

- $\mathrm{p}_{i, t}=$ Variável dependente, representada pelo preço da ação da empresa $i$, no tempo $t$;

- $\alpha_{0}=$ Intercepto;

- $\quad a_{1}=$ Coeficiente de inclinação para o LLPA ou o PLPA;

- $\quad L L P A=$ Variável independente, representada pela divisão do Lucro Líquido (LL), advindo da Demonstração do Resultado do Exercício (DRE), pelo número de ações da empresa $i$, no tempo $t$;

- $\quad P L P A=$ Variável independente, representada pela divisão do Patrimônio Líquido (PL), advindo do BP, pelo número de ações da empresa $i$, no tempo $t$;

- $\varepsilon=$ Erro aleatório (ruído branco) com distribuição normal, média zero e variância constante.

Para a análise de regressão, basicamente, consideraram-se os valores do $\mathrm{R}^{2}$, dos critérios informacionais de Akaike e de Schwarz e dos p-valores do teste $F$ (significância do $\mathrm{R}^{2}$ ) e do teste $t$ (significância do coeficiente angular da variável independente).

Segundo Gujarati (2006), Corrar, Paulo e Dias Filho (2007) e Fávero, Belfiore, Silva e Chan (2009) a análise do $\mathrm{R}^{2}$ mostra o poder de explicação da variável dependente pelas variáveis independentes. Já os critérios informacionais de Akaike e de Schwarz mostram a qualidade de ajustamento do modelo, sendo ambos do tipo quanto menor, melhor. Por fim, os p-valores dos testes $F$ e $t$ mostram se as variáveis independentes em conjunto e individualmente, respectivamente, são estatisticamente capazes de explicar o comportamento da variável dependente.

Para o caso dos pressupostos da regressão simples, conforme indicado por Gujarati (2006), Corrar, Paulo e Dias Filho (2007) e Fávero et al. (2009), para testar a normalidade dos resíduos, utilizou-se o teste de Jarque-Bera (JB) e para testar a homocedasticidade dos resíduos, utilizou-se o teste de BreuschPagan-Godfrey (BPG). Cabe ressaltar que, segundo Fávero et al. (2009), de maneira geral, não se faz necessário testar a autocorrelação dos resíduos, quando os dados estão em cross-section, como no caso da presente pesquisa.

Para os casos em que se encontrou problema de heterocedasticidade dos resíduos, utilizou-se a correção de White, que, segundo Gujarati (2006), corrige os erros-padrão dos coeficientes, tornando-os consistentes para heterocedasticidade. Para análise das diferenças nos indicadores, foi utilizado o software SPSS 17.0, enquanto que para a análise da relevância das informações contábeis foi utilizado Eviews 6.0. 


\section{Análise dos Resultados}

Como dito anteriormente, a análise acontece em duas fases: (i) procura-se verificar se existem diferenças estatisticamente significativas entre os indicadores calculados com informações de 2009 em BRGAAP (publicadas em 2010) e com informações full IFRS (reapresentadas em 2011); (ii) procura-se analisar o impacto do IFRS no conteúdo informacional da Contabilidade pela análise da capacidade do LL e do PL explicarem o comportamento do preço das ações.

$\mathrm{Na}$ análise sobre as diferenças existentes nos principais indicadores contábil-financeiros, o primeiro passo foi calcular os valores médios e as medianas de cada indicador, para, numa análise preliminar, observar o comportamento dos índices com as informações nos dois GAAPs.

Pelos resultados das Tabelas 1 e 2, pode-se perceber que apenas a participação de capital de terceiros (PCT) apresenta distribuição tendendo à normal, Já para os resultados dos testes não paramétricos de diferença de médias, em ambos os testes, percebe-se que as diferenças só se mostram significativas ao nível de 5\% para os indicadores de Endividamento, Giro do Ativo, Margem Bruta, Fluxo de Caixa Operacional sobre o Ativo Total e Fluxo de Caixa Operacional sobre o Patrimônio Líquido.

Em relação aos indicadores que mostraram alteração significativa pela adoção do IFRS, pode-se perceber que, em todos os casos, tanto a média, quanto a mediana, mostraram-se menores com os dados publicados em full IFRS, resultado contrário ao encontrado por Braga et al. (2011), que observaram um aumento no índice de endividamento. No entanto, coerente aos achados de Haller, Ernstberger e Froschhammer (2009).

Tabela 1

Médias e Medianas para os Indicadores

\begin{tabular}{ccccc}
\hline \multirow{2}{*}{ Indicador } & \multicolumn{2}{c}{ Médias } & \multicolumn{2}{c}{ Medianas } \\
\cline { 2 - 5 } & Dados 09-10 & Dados 09-11 & Dados 09 - 10 & Dados 09 - 11 \\
\hline PCT & 0,6043 & 0,5920 & 0,5528 & 0,5482 \\
\hline END & 1,8218 & 1,5007 & 1,1760 & 1,1525 \\
\hline LG & 1,2276 & 1,3031 & 0,9628 & 1,9772 \\
\hline LC & 2,0201 & 2,0380 & 1,7583 & 0,5335 \\
\hline GA & 0,7296 & 0,6827 & 0,5794 & 0,3247 \\
\hline MB & 0,3568 & 0,3547 & 0,3256 & 0,0949 \\
\hline ML & 0,0236 & 0,0422 & 0,0836 & 0,0531 \\
\hline RSA & 0,0413 & 0,0482 & 0,0517 & 0,1330 \\
\hline RSPL & 0,1587 & 0,1415 & 0,1392 & 0,0679 \\
\hline FSA & 0,0707 & 0,0580 & 0,0835 & 0,1487 \\
\hline FSP & 0,2572 & 0,2095 & 0,1804 & \\
\hline
\end{tabular}

Fonte: Dados da Pesquisa 
Tabela 2

\section{Resultados para os Testes de Diferença de Médias para os Indicadores}

\begin{tabular}{ccccc}
\hline \multirow{2}{*}{ Indicador } & \multicolumn{2}{c}{ p-valor } & \multicolumn{2}{c}{ p-valor } \\
\cline { 2 - 5 } & Teste K-S 09-10 & Teste K-S 09-11 & Teste de Wilcoxon & Teste do Sinal \\
\hline PCT & 0,2000 & 0,2000 & 0,1660 & 0,8600 \\
\hline END & 0,0000 & 0,0000 & 0,0050 & 0,0430 \\
\hline LG & 0,0000 & 0,0000 & 0,9450 & 0,7290 \\
\hline LC & 0,0000 & 0,0000 & 0,0970 & 0,1160 \\
\hline GA & 0,0000 & 0,0000 & 0,0000 & 0,0000 \\
\hline MB & 0,0000 & 0,0000 & 0,0120 & 0,0150 \\
\hline ML & 0,0000 & 0,0000 & 0,2250 & 0,1710 \\
\hline RSA & 0,0000 & 0,0000 & 0,4230 & 0,7310 \\
\hline RSPL & 0,0000 & 0,0000 & 0,2380 & 0,2250 \\
\hline FSA & 0,0010 & 0,0000 & 0,0000 & 0,0000 \\
\hline FSPL & 0,0000 & 0,0000 & 0,0000 & 0,0000 \\
\hline
\end{tabular}

Fonte: Dados da Pesquisa

Continuando, aplicou-se a análise de regressão às informações de LL, PL e preço das ações. Preliminarmente, em relação aos pressupostos da regressão, observa-se que, em todos os casos, têm-se problemas de normalidade dos resíduos, conforme resultados do teste de Jarque-Bera (JB) nas Tabelas 3 e 4. Porém, de acordo com o teorema do limite central e considerando que foram utilizadas 148 observações, esse pressuposto pode ser relaxado (Brooks, 2002). Já em relação à heterocedasticidade, conforme resultados dos testes de Breusch-Pagan-Godfrey (BPG), pode-se perceber que, nas regressões com os dados de 2009 apresentados em 2010, os resíduos não se apresentam homocedásticos. Para esses casos, os resultados já estão apresentados, considerando-se a correção de White para heterocedasticidade. Já na regressão com os dados de PLPA de 2009 publicados em 2011, apesar de ter-se um p-valor para o teste BPG superior ao nível de significância de 5\%, o que levaria a não rejeição da hipótese de homocedasticidade dos resíduos, adotou-se, por precaução, a apresentação dos resultados com a aplicação da correção de White.

Tabela 3

\section{Dados para o LLPA}

\begin{tabular}{|c|c|c|c|c|}
\hline Variável Explicativa ou Independente & Coeficiente & Erro Padrão* & $t^{*}$ & p-value* \\
\hline LLPA 09-10 & 1,9064 & 0,9274 & 2,0557 & 0,0416 \\
\hline C & 15,1591 & 1,4261 & 10,6295 & 0,0000 \\
\hline Informações Adicionais & Valores & Informações Adicionais & & Valores \\
\hline $\mathrm{R}^{2}$ & 0,1366 & Critério Informacional de Akaike & & 7,6763 \\
\hline $\mathrm{F}(p$-value $)$ & 0,0000 & Critério Informacional de Schwarz & & 7,7168 \\
\hline Jarque-Bera ( $p$-value) & 0,0000 & Breusch-Pagan-Godfrey ( $p$-value) & & 0,0021 \\
\hline Variável Explicativa ou Independente & Coeficiente & Erro Padrão & $\mathbf{t}$ & p-value \\
\hline LLPA 09-11 & 1,7886 & 0,2902 & 6,1629 & 0,0000 \\
\hline C & 14,7092 & 0,9587 & 15,3437 & 0,0000 \\
\hline Informações Adicionais & Valores & Informações Adicionais & & Valores \\
\hline $\mathrm{R}^{2}$ & 0,2064 & Critério Informacional de Akaike & & 7,5919 \\
\hline $\mathrm{F}(p$-value $)$ & 0,0000 & Critério Informacional de Schwarz & & 7,6324 \\
\hline Jarque-Bera ( $p$-value) & 0,0000 & Breusch-Pagan-Godfrey ( $p$-value) & & 0,1531 \\
\hline
\end{tabular}

* Estimado com correção de White para heterocedasticidade

Fonte: Dados da Pesquisa 
Pela análise dos resultados apresentados na Tabela 3, pode-se perceber que tanto os dados de LLPA de 2009 apresentados em 2010, quanto os dados reapresentados em 2011, se mostraram estatisticamente significativos na explicação do comportamento do preço das ações, visto que o p-valor dos testes $F$ e $t$ se mostraram inferiores ao nível de significância de 5\%. Portanto, não se pode rejeitar a hipótese nula de que o $\mathrm{R}^{2}$ é diferente de zero e de que o coeficiente angular da variável independente LLPA também é diferente de zero. Ou seja, o lucro, seja ele apurado com base no full IRFRs, ou não, é uma boa medida para explicar o comportamento do preço das ações.

Porém, uma comparação do poder de explicação do preço pelo LLPA, pode-se perceber que tanto o valor do $\mathrm{R}^{2}$, quanto os valores dos critérios informacionais de Akaike e de Schwarz, mostram superioridade dos dados apresentados em 2011. Isso porque os dados publicados em 2010 são capazes de explicar 13,66\% da variação do preço das ações, enquanto que as informações de LLPA de 2009 apresentadas em 2011 explicam 20,64\% da variação dessa variável dependente. Tem-se, então, alteração significativa na capacidade do Lucro em explicar o preço das ações.

Essa constatação é corroborada pela análise dos critérios informacionais, pois em ambos os casos (Akaike e Schwarz) tem-se redução dos valores de 2010 para 2011, o que mostra maior capacidade informacional do LLPA para explicar o comportamento dos preços das ações das empresas.

Em síntese, isso mostra que, com a adoção do IFRS, o LLPA passa a ter maior capacidade explicativa do comportamento dos preços das ações no mercado brasileiro de capitais.

Já em relação ao PLPA, os resultados apresentados na Tabela 4 também mostram que tanto os dados de 2009 publicados em 2010, quanto os dados reapresentados em 2011, são significativos na explicação do comportamento do preço das ações das empresas. Isso pode ser observado pelos valores dos p-valores dos testes $F$ e $t$, que se mostraram inferiores ao nível de significância de $5 \%$, fazendo com que a regressão como um todo se apresentasse significativa, bem como o coeficiente angular do PLPA.

Tabela 4

\section{Dados para o PLPA}

\begin{tabular}{|c|c|c|c|c|}
\hline Variável Explicativa ou Independente & Coeficiente & Erro Padrão* & $t^{*}$ & p-value* \\
\hline PLPA 09-10 & 0,6569 & 0,1459 & 4,5039 & 0,0000 \\
\hline C & 11,2268 & 1,2994 & 8,6768 & 0,0000 \\
\hline Informações Adicionais & Valores & Informações Adicionais & & Valores \\
\hline $\mathrm{R}^{2}$ & 0,3152 & Critério Informacional de Akaike & & 7,4445 \\
\hline $\mathrm{F}(p$-value $)$ & 0,0000 & Critério Informacional de Schwarz & & 7,4850 \\
\hline Jarque-Bera ( $p$-value) & 0,0000 & Breusch-Pagan-Godfrey ( $p$-value) & & 0,0001 \\
\hline Variável Explicativa ou Independente & Coeficiente & Erro Padrão* & $t^{*}$ & p-value \\
\hline PLPA 09-11 & 0,5259 & 0,0779 & 6,7538 & 0,0000 \\
\hline C & 11,5848 & 1,0100 & 11,4706 & 0,0000 \\
\hline Informações Adicionais & Valores & Informações Adicionais & & Valores \\
\hline $\mathrm{R}^{2}$ & 0,3083 & Critério Informacional de Akaike & & 7,4546 \\
\hline $\mathrm{F}(p$-value $)$ & 0,0000 & Critério Informacional de Schwarz & & 7,4951 \\
\hline Jarque-Bera ( $p$-value) & 0,0000 & Breusch-Pagan-Godfrey ( $p$-value) & & 0,0556 \\
\hline
\end{tabular}

* Estimado com correção de White para heterocedasticidade

Fonte: Dados da Pesquisa 
Porém, uma diferença importante em relação aos dados do LLPA é que, no caso do PLPA, os $\mathrm{R}^{2} \mathrm{e}$ os critérios informacionais de Akaike e de Schwarz, não se mostram diferentes. No caso do poder de explicação do comportamento do preço das ações pelo PLPA observa-se que, tanto as informações publicadas em 2010, quanto às reapresentadas em 2011, pouco mais de 30\% da variação do preço das ações pode ser explicada pela variação do PLPA. Ou seja, apesar da redução do poder de explicação e do conteúdo explicativo dos dados publicados em 2010 para os dados reapresentados em 2011, essa redução não sustenta afirmação de alteração do conteúdo informacional do PLPA.

\section{Conclusões}

O estudo teve por objetivo analisar o impacto do processo de convergência às normas contábeis internacionais no Brasil sobre o conteúdo informacional da Contabilidade, tendo como base duas perspectivas: as mudanças causadas nos principais índices contábil-financeiros e as alterações no poder explicativo das informações contábeis no LL e PL para o mercado brasileiro de capitais.

Para atingir o objetivo proposto, foi necessário seu desmembramento em dois objetivos específicos: (i) verificar se existem indícios de diferença significativa entre os índices calculados para as informações de 2009 publicadas em 2010 e as reapresentadas em 2011; (ii) verificar se existem indícios de mudança no poder explicativo do preço das ações das empresas no mercado brasileiro de capitais, quando do uso das informações de 2009 publicadas em 2010 e as reapresentadas em 2011.

Os resultados apontaram que os indicadores Endividamento (END), Giro do Ativo (GA), Margem Bruta (MB), Fluxo de Caixa Operacional sobre Ativo Total (FSA) e Fluxo de Caixa Operacional sobre Patrimônio Líquido (FSPL) mostraram-se menores, quando utilizado dados das demonstrações em full IFRS. Os achados corroboram a pesquisa de Santos e Calixto (2010), que detectaram lucros superiores com a adoção das IFRS, o que explicam com a redução do conservadorismo contábil. Por outro lado, os resultados contrariando os achados de Braga et al. (2011), que observaram aumento significativo no índice de endividamento. De todo modo, os resultados são coerentes com pesquisas anteriores (Silva, Couto \& Cordeiro 2009; Haller, Ernstberg \& Froschhammer, 2009).

Analisado a capacidade informacional do LLPA, por meio de regressão, foi possível detectar que, ao aplicar todas as IFRS, o LLPA aumenta seu poder explicativo. Possivelmente, esse fato deve-se ao lucro, com base no padrão IFRS, representar mais adequadamente a realidade econômica das empresas, ou seja, a migração para o padrão full IFRS trouxe alterações no conteúdo informacional do lucro no sentido de incorporar informações já consideradas pelos investidores na formação dos preços das ações. Esses achados corroboram com estudos precedentes (Barth, Landsman \& Lang, 2008; Morais \& Curto, 2009; Chalmers, Clinch \& Godfrey; 2009; Macedo, Machado \& Machado (2011).

Em relação ao conteúdo informacional do PLPA, os resultados apontaram que não houve alteração significativa no seu poder explicativo. Desse modo, levanta-se a hipótese de que o conjunto de alterações no PL, por conta da adoção do padrão full IFRS, não é relevante para o mercado de capitais.

Limitação relevante para o estudo é o fato de que algumas empresas já poderiam ter apresentado suas informações de 2009 em full IFRS desde a publicação em 2010. Com isso, para essas empresas não haveria diferença a ser estudada. Adicionalmente, não fez parte do escopo do estudo, representando, assim, também uma limitação, se havia alguma alteração das informações de 2009 publicadas em 2010 nas informações reapresentadas em 2011. Admitiu-se, portanto, que não houve significativa adesão antecipada por parte das empresas ao padrão full IFRS e que, de maneira geral, as informações de 2009 reapresentadas em 2011 tem como alterações apenas aquelas oriundas das mudanças no padrão contábil vigente no Brasil.

Sugere-se que em futuros estudos procure-se analisar os determinantes de variação positiva ou negativa de alguns indicadores em cada empresa, buscando entender o impacto da adoção das IFRS no Brasil. 


\section{Referências}

Assaf Neto, A. (2006). Estrutura e Análise de Balanços: um enfoque econômico-financeiro. (8 ed.) São Paulo: Atlas.

Baptista, E. M. B. (2009) Ganhos em transparência versus novos instrumentos de manipulação: o paradoxo das modificações trazidas pela Lei no 11.638. RAE - Revista de Administração de Empresas, 49(2), p. 234-239.

Barth, M. E., Landsman, W. R. \& Lang, M. H. (2008). International accounting standards and accounting quality. Journal of Accounting Research, 46(3), p. 467-498.

Bartov, E., Goldberg, S. R. \& KIM, M. (2005). Comparative Value Relevance Among German, U.S., and International Accounting Standards: A German Stock Market Perspective. Journal of Accounting, Auditing \& Finance, 20(2), p. 95-119.

Braga, H. R. (2003). Demonstrações Contábeis: Estrutura, Análise e Interpretação. (5 ed.) São Paulo: Atlas.

Braga, J. P., Araujo, M. B. V., Macedo, M. A. S. \& Corrar, L. J. (2011). Análise do Impacto das Mudanças nas Normas Contábeis Brasileiras: um estudo comparativo dos indicadores econômico-financeiros de companhias brasileiras para o ano de 2007. RCC - Revista Contemporânea de Contabilidade, 8(15), p. 105-128.

Brooks, C. (2002). Introductory econometrics for finance. Cambridge: Cambridge University Press.

Callao, S., Jarne, J.I. \& Laínez, J.A. (2007). Adption of IFRS in Spain: Effect on the comparability and relevance of financial reporting. Journal of International Accounting, Auditing and Taxation, 16(2), p.148-178.

Carvalho, L.N., Lemes, S. \& Costa, F. M. (2008). Contabilidade Internacional: aplicação das IFRS 2005. São Paulo. Atlas.

Chalmers, K., Clinch, G. J. \& Godfrey, J. M. (2008). Adoption of International Financial Reporting Standards: Impact on the Value Relevance of Intangible Assets. Australian Accounting Review. 18(3), p. 237-247.

Chalmers, K., Clinch, G. J. \& GODFREY, J. M. (Janeiro 2009). Changes in Value Relevance of Financial Information Upon IFRS Adoption. Social Science Research Network (SSRN). Recuperado em 23 agosto de 2010 www.ssrn.com.

Circular Susep n 357, de 26 de dezembro de 2007 (2007). Dispõe sobre o processo de convergência às normas internacionais de contabilidade. Rio de Janeiro: Superintendência de Seguros Privados. Recuperado em 20 março de 2012 de http://www.cpc.org.br/pdf/circ357_susep.pdf.

Collis, D., Maydew, E. L. \& Weiss, L. (1997). Changes in the value relevance of earnings and book value over the past forty years. Journal of Accounting and Economics. 24(1), p. 39-67.

COMITÊ DE PRONUNCIAMENTOS CONTÁBEIS (CPC) (2011). Pronunciamento conceitual básico: estrutura conceitual para a elaboração e apresentação das demonstrações contábeis. Brasília,.

Comitê de Pronunciamentos Contábeis (CPC). (2011). Pronunciamento conceitual básico: estrutura conceitual para a elaboração e apresentação das demonstrações contábeis. Brasília, DF: Autor.

Comunicado Bacen $n .^{\circ}$ 14.259/06 (2006). Comunica procedimentos para a convergência das normas de contabilidade e auditoria aplicáveis às instituições financeiras e às demais instituições autorizadas a funcionar pelo Banco Central do Brasil com as normas internacionais promulgadas pelo International Accounting Standards Board (IASB) e pela International Federation of Accountants (IFAC). Brasilia, DF: Banco Central do Brasil. Recuperado em 20 de março de 2012 de http://www.fiscosoft. com.br/index.php?PID=143114\&amigavel=1\#ixzz2aYAEh5WJ.

Corrar, L. J., Paulo, E. \& Dias Filho, J. M. (Coords.). (2007). Análise Multivariada para Cursos de Administração, Ciências Contábeis e Economia. São Paulo: Atlas.

Costa, F. M. \& Lopes, A. B. (2007). Ajustes aos US-GAAP: estudo empírico sobre sua relevância para empresas brasileiras com ADRs negociadas em bolsa de Nova Iorque. Revista Contabilidade \& Finanças, 18(Esp.), p. 45-57. 
Ding, Y., Hope, O. K., Jeanjean, T. \& Stolowy, H. (2007). Differences Between Domestic Accounting Standards and IAS: Measurement, Determinants and Implications. Journal of Accounting and Public Policy, 26(1), p. 1-38.

Fávero, L. P., Belfiore, P., Silva, F. L. da \& Chan, B. L. (2009). Análise de dados - modelagem multivariada para tomada de decisões. Rio de Janeiro: Campus/Elsevier.

Grecco, M. C. P., Geron, C. M. S.\& Formigoni, H. (2009). O Impacto das Mudanças nas Práticas Contábeis no Nível de Conservadorismo das Companhias Abertas Brasileiras. Anais do Congresso Brasileiro de Custos, 16. Fortaleza, CE, Brasil.

Gujarati, D. (2006). Econometria Básica. Rio de Janeiro: Campus/Elsevier.

Haller, A.; Ernstberger, J. \& Froschhammer, M. (2009). Implications of the Mandatory Transition from National GAAP to IFRS - Empirical Evidence from Germany. Advances on Accounting, Incorporate Advances in Internacional Accounting.25(2), 226-236.

Hung, M. \& SUBRAMANYAM, K. R. (2007). Financial statement effects of adopting international accounting standards: the case of Germany. Review of Accounting Studies, 12(4), p. 623-657.

Instrução CVM ñ 457, de 13 de julho de 2007 (2007). Dispõe sobre a elaboração e divulgação das demonstrações financeiras consolidadas, com base no padrão contábil internacional emitido pelo International Accounting Standards Board - IASB. Rio de Janeiro: Comissão de Valores Mobiliários. Recuperado em 20 março, 2012 de www.cvm.gov.br/asp/cvmwww/atos/Atos/inst/inst457.doc.

Iudícibus, S. (2008). Análise de Balanços. (9 ed.) São Paulo: Atlas.

Iudícibus, S. (2010). Teoria da Contabilidade. (10 ed.) São Paulo: Atlas.

Iudícibus, S., Martins, E, \& Carvalho, L. N. (2005). Contabilidade: aspectos relevantes da epopéia de sua evolução. Revista de Contabilidade \& Finanças, 16(38), p. 7-19.

Iudícibus, S., Martins, E, Gelbcke, E. R. \& Santos, A. (2010). Manual de Contabilidade Societária. São Paulo: Atlas.

Klann, R. C. \& Beuren, I. M. (2011). Efeitos da Convergência Contábil às IFRS no Gerenciamento de Resultados de Empresas Européias. Anais do Congresso Anpcont, 5. Vitória, ES, Brasil.

Lang, M., Raedy, J. \& Yetman, M. (2003). How representative are firms that are cross listed in the United States? An analysis of accounting quality. Journal of Accounting Research, 41(2), p. 363-386.

Lantto, A. M. \& Sahlström, P. (2009). Impact of International Financial Reporting Standard Adoption on Key Financial Ratios. Accounting and Finance. 49(2), 341-361.

Lei $n .{ }^{\circ} 11.638$, de 28 de dezembro de 2007 (2007). Altera e revoga dispositivos da Lei n. ${ }^{\circ} 6.404$, de 17 de dezembro de 1976, e da Lei n. ${ }^{\circ} 6.385$, de 7 de dezembro de 1976, e estende às sociedades de grande porte disposições relativas à elaboração e divulgação de demonstrações financeiras. Brasília, DF: Poder Executivo. Recuperado em 20 março, 2012 de http://www.planalto.gov.br.

Lei . $^{\circ} 6.404$ de 17 de dezembro de 1976 (1976). Dispõe sobre as sociedades por ações. . Brasília, DF: Poder Executivo. Recuperado em 20 março, 2012 de http://www.planalto.gov.br.

Lima, J. B. N. (2010). A relevância da informação contábil e o processo de convergência para as normas IFRS no Brasil. Tese (Doutorado em Ciências Contábeis) - Universidade de São Paulo, Faculdade de Economia e Administração. São Paulo, SP.

Lopes, A. B. (2002). A Informação Contábil e o Mercado de Capitais. São Paulo: Pioneira Thomson Learning.

Macedo, M. A. S, Machado, M. A. V., Murcia, F. D. R. \& Machado, M. R. (2011). Análise do impacto da substituição da DOAR pela DFC: um estudo sob a perspectiva do value-relevance. Revista de Contabilidade e Finanças, 22(57), p. 299-318. 
Macedo, M. A. S., Machado, M. A. V. \& Machado, M. R. (2011). Análise da Relevância da Informação Contábil no Brasil num Contexto de Convergência às Normas Internacionais de Contabilidade. Anais do Congresso Nacional de Administração e Ciências Contábeis - ADCONT, 2. Rio de Janeiro, RJ, Brasil.

Marques, J. A. V. C., Carneiro Junior, J. B. A. \& Kühl, C. A. (2008). Análise Financeira das Empresas: da abordagem financeira tradicional às medidas de criação de valor. Rio de Janeiro: Freitas Bastos.

Martins, G. A. \& Theóphilo, C. R. (2009). Metodologia da Investigação Científica para Ciências Sociais Aplicadas. (2 ed.) São Paulo: Atlas.

Matarazzo, D. C. (2003). Análise Financeira de Balanços: abordagem básica e gerencial. (6 ed.) São Paulo: Atlas.

Miranda, V. L. (2008). Impacto da adoção das IFRS (International Financial Reporting Standards) em indicadores econômico-financeiros de bancos de alguns países da União Européia. 2008. 114 f. Dissertação (Mestrado em Ciências Contábeis) - Universidade de São Paulo, Faculdade de Economia e Administração, São Paulo, SP.

Morais, A. I. \& Curto, J. D. (2008). Accounting quality and the adoption of IASB Standards - portuguese evidence. Revista Contabilidade \& Finanças, 19(48), p. 103-111.

Morais, A. I. \& Curto, J. D. (2009). Mandatory adoption of IASB Standards: value relevance and country-specific factors. Australian Accounting Review, 19(49), p. 128-143.

Niskanen, J., Kinnunen, J. \& Kasanen, E. (2000). The value relevance of IAS reconciliation components: empirical evidence from Finland. Journal of Accounting and Public Policy, 19(2), p. 119-137.

Niyama, J. K. (2006). Contabilidade Internacional. São Paulo: Atlas.

Pereira da Silva, J. (2008). Análise Financeira das Empresas. (9 ed.) São Paulo: Atlas.

Perez Jr., J. H. \& Begalli, G. (2002). A. Elaboração das Demonstrações Contábeis. (3 ed.) São Paulo: Atlas.

Perramon, J. \& AMAT, O. (2006). IFRS Introduction and its Effect on Listed Companies in Spain. Economics Working Papers, no. 975, Universitat Pompeu Fabra, Department of Economics and Business. Recuperado em 09 fevereiro, 2012 de http://www.econ.upf.edu/docs/papers/downloads/975.pdf.

Plöger, A. Palavra do CPC. (2005). Recuperado em 31 março, 2012 de http://www.cpc.org.br/palavra.htm.

Resolução no 1.055, de 07 de outubro de 2005. (2005). Cria o Comitê de Pronunciamentos Contábeis $(\mathrm{CPC})$, e dá outras providências.. Brasília, DF: Conselho Federal de Contabilidade. Recuperado em 20 março, 2012 de http://www.cgu.gov.br/PrevencaodaCorrupcao/Integridade/IntegridadeEmpresas/arquivos/RES_1055.pdf.

Santos, E. S. \& Calixto, L. (2010). Impactos do Início da Harmonização Contábil Internacional (Lei n. ${ }^{\circ}$ 11.638/07) nos Resultados de Empresas Abertas. RAE-eletronica, 9(1).

Siegel, S. \& Castellan Jr., N. J. (2006). Estatística Não-Parmétrica para as Ciências do Comportamento. (2 ed) Porto Alegre: Bookman.

Silva, F. J. F, Couto, G. M. M. \& Cordeiro, R. M. (2009). Measuring the Impact of International Financial Reporting Standards (IFRS) to Financial Information of Portuguese Companies. Revista Universo Contábil, 5(1), p. 129-144.

Van der Meulen, S., Gaeremynck, A. \& Willekens, M. (2007). Attribute differences between U.S. GAAP and IFRS earnings: an exploratory study. The International Journal of Accounting, 42(2), p. 123-142.

Vergara, S. C. (2010). Projetos e relatórios de pesquisa em administração. (12 ed.) São Paulo: Atlas.

Vishnani, S. \& Shah, B. Kr. (2008). Value relevance of published financial statements - with special emphasis on impact of cash flow reporting. International Research Journal of Finance and Economics, 3(17), p. 84-90.

Weffort, E. F. J. (2005). O Brasil e a Harmonização Contábil Internacional. São Paulo: Atlas. 
Apêndice 01. Principais Mudanças nas Práticas Contábeis

\begin{tabular}{|c|c|c|c|}
\hline Assunto & Antes do Processo de Convergência & Após o Processo de Convergência & $\begin{array}{l}\text { Componentes das } \\
\text { Demonstrações } \\
\text { Contábeis } \\
\text { potencialmente } \\
\text { afetados por } \\
\text { essas alterações / } \\
\text { Potencial efeito }\end{array}$ \\
\hline $\begin{array}{l}\text { Estrutura } \\
\text { Conceitual para } \\
\text { Elaboração e } \\
\text { Divulgação de } \\
\text { Relatório Contábil- } \\
\text { Financeiro }\end{array}$ & $\begin{array}{l}\text { Princípios fundamentais de contabilidade: } \\
\text { entidade; continuidade; oportunidade; } \\
\text { registro pelo valor original; atualização } \\
\text { monetária; competência; e prudência. } \\
\text { Atributos da informação contábil: } \\
\text { confiabilidade; tempestividade; } \\
\text { compreensibilidade; e comparabilidade. }\end{array}$ & $\begin{array}{l}\text { Características qualitativas da informação } \\
\text { contábil dividida em : (a) características } \\
\text { qualitativas fundamentais - relevância e } \\
\text { representação fidedigna; e (b) características } \\
\text { qualitativas de melhoria - comparabilidade, } \\
\text { verificabilidade, tempestividade e } \\
\text { compreensibilidade. }\end{array}$ & Não se aplica \\
\hline $\begin{array}{l}\text { Teste de } \\
\text { Recuperabilidade }\end{array}$ & Não previsto. & $\begin{array}{l}\text { Os ativos não podem estar contabilizados por } \\
\text { valor superior ao seu valor recuperável. Caso } \\
\text { exista evidências de desvalorização, deve-se } \\
\text { reconhecer a perda estimada. }\end{array}$ & $\begin{array}{l}\text { Ativo Não Circulante } \\
\text { (redução) e Resultado } \\
\text { (redução) }\end{array}$ \\
\hline $\begin{array}{l}\text { Demonstração dos } \\
\text { Fluxos de Caixa }\end{array}$ & Demonstração não obrigatória. & $\begin{array}{l}\text { A Demonstração dos Fluxos de Caixa passa a } \\
\text { ser obrigatória, em substituição à DOAR. }\end{array}$ & Nova demonstração \\
\hline Ativo Intangível & Não previsto. & $\begin{array}{l}\text { Ativos não corpóreos, desde que atendam aos } \\
\text { critérios estabelecidos no CPC } 4 \text {, devem ser } \\
\text { registrados no ativo intangível. }\end{array}$ & $\begin{array}{l}\text { Ativo Não Circulante } \\
\text { (aumento ou neutro) }\end{array}$ \\
\hline $\begin{array}{l}\text { Arrendamento } \\
\text { Mercantil }\end{array}$ & $\begin{array}{l}\text { Prestação lançada integralmente como } \\
\text { despesa, quando incorrida. }\end{array}$ & $\begin{array}{l}\text { Arrendamento mercantil classificado } \\
\text { como financeiro deve ser contabilizado } \\
\text { como compra financiada, ocasionando } \\
\text { na contabilização do ativo, da respectiva } \\
\text { depreciação, e das despesas de juros } \\
\text { referentes á transação. Para o arrendamento } \\
\text { caracterizado como operacional, o tratamento } \\
\text { permanece o mesmo. }\end{array}$ & $\begin{array}{l}\text { Ativo Não Circulante } \\
\text { (aumento) e Resultado } \\
\text { (aumento pela } \\
\text { depreciação e redução } \\
\text { pela parcela) }\end{array}$ \\
\hline $\begin{array}{l}\text { Subvenções } \\
\text { e Assistência } \\
\text { Governamentais }\end{array}$ & Reconhecidas como Reserva de Capital & $\begin{array}{l}\text { Todas as subvenções passam a ter que } \\
\text { tramitar pelo resultado, havendo diferenças } \\
\text { no momento do reconhecimento, conforme } \\
\text { condições de cada subvenção. }\end{array}$ & $\begin{array}{l}\text { Patrimônio Líquido } \\
\text { (redução) e Resultado } \\
\text { (redução) }\end{array}$ \\
\hline $\begin{array}{l}\text { Custos de } \\
\text { Transação e Prêmio } \\
\text { na Emissão de } \\
\text { Títulos e Valores } \\
\text { Mobiliários }\end{array}$ & $\begin{array}{l}\text { Os bônus de subscrição e prêmio na } \\
\text { emissão de debêntures eram lançados } \\
\text { como Reserva de Capital. Custos de } \\
\text { transação eram reconhecidos como } \\
\text { despesas. }\end{array}$ & $\begin{array}{l}\text { Os custo de transação passam a ser } \\
\text { classificados, de forma destacada, conta } \\
\text { retificadora do Capital Social ou, quando } \\
\text { aplicável, na Reserva de Capital que registrar o } \\
\text { prêmio recebido na emissão das novas ações. } \\
\text { Os títulos de dívida devem ser evidenciados } \\
\text { pelo valor líquido disponível para utilização, } \\
\text { reconhecidos imediatamente em contas } \\
\text { retificadoras e apropriados ao resultado em } \\
\text { função da fluência do prazo da operação, com } \\
\text { base na taxa interna de retorno (TIR). }\end{array}$ & $\begin{array}{l}\text { Patrimônio Líquido } \\
\text { (redução), Reserva } \\
\text { de Capital (aumento), } \\
\text { Passivo Exigível } \\
\text { (redução) e Resultado } \\
\text { (aumento) }\end{array}$ \\
\hline $\begin{array}{l}\text { Demonstração do } \\
\text { Valor Adicionado }\end{array}$ & Demonstração não obrigatória. & $\begin{array}{l}\text { Demonstração obrigatória para companhias } \\
\text { abertas, empresas reguladas pela ANEEL, } \\
\text { ANTT e ANS }\end{array}$ & Nova demonstração \\
\hline $\begin{array}{l}\text { Pagamento } \\
\text { Baseado em Ações }\end{array}$ & $\begin{array}{l}\text { Era reconhecida no resultado, quando a } \\
\text { opção era exercida. }\end{array}$ & $\begin{array}{l}\text { Devem ser reconhecidos como despesa, } \\
\text { mensurados a valor justo, no momento em } \\
\text { que são outorgados, em contrapartida a conta } \\
\text { Instrumentos Patrimoniais Outorgados, no } \\
\text { Patrimônio Líquido. }\end{array}$ & $\begin{array}{l}\text { Patrimônio Líquido } \\
\text { (aumento ou redução) }\end{array}$ \\
\hline
\end{tabular}




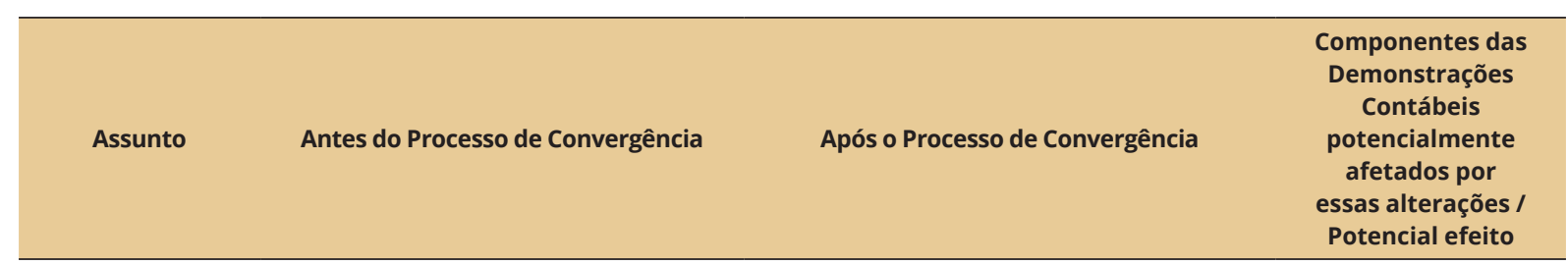

Ativo não Circulante

(redução), Passivo não

Ajuste a Valor Presente

Não previsto.
Obrigatoriedade do ajuste a valor presente nos realizáveis e exigíveis a longo prazo e no caso de efeito relevante, também nos de curto prazo.
Circulante (redução) e

Resultado (aumento, em contrapartida de ativos, ou redução, em contrapartidas de passivos).

Esse grupo foi extinto. Os saldos referentes a itens que mudaram de classificação deveriam ter sido reclassificados. Os saldos referentes a itens que não podem mais ser ativados, puderam ser lançados contra os lucros ou prejuízos acumulados ou ficar nesse grupo até sua amortização final.

Era permitido que despesas como gastos de implantação e pré-operacionais, gastos

Ativo Diferido e gastos reorganizacionais fossem capitalizados e amortizados em prazo não superior a dez anos.

A reavaliação espontânea foi extinta. Os saldos remanescentes na Reserva de Reavaliação deveriam ser transferidos para lucros ou prejuízos acumulados na proporção da baixa dos ativos a que se referem.
Reavaliação de Ativos Imobilizados

Era permitida a reavaliação de ativos imobilizados, em contrapartida a Reserva de Reavaliação.
Eram avaliados pelo método da equivalência patrimonial os investimentos relevantes em sociedades coligadas sobre cuja administração tivesse influência, ou de que participasse com $20 \%$ ou mais do capital social, e em sociedade controladas.

Equivalência Patrimonial Investimentos
Registrados e mantidos pelo custo histórico. equivalência patrimonial os investimentos em coligadas, coligadas e em outras sociedades que façam parte de um mesmo grupo ou estejam sob controle comum.
Devem ser avaliados pelo método da
Patrimônio Líquido

(redução)
Mensurado inicialmente pelo custo. Após o reconhecimento inicial, a entidade pode optar justo. As variações no valor justo devem ser reconhecidas diretamente no resultado do período em que ocorrem. pelo método do custo ou o método do valor
Patrimônio Líquido (redução) (aumentar ou reduzir) e Resultado (aumentar ou reduzir).

Ativo Circulante (aumento ou redução) e Resultado (aumento ou redução)

Ativo Circulante e Não circulante (aumento ou redução), Passivo Circulante e Não

A mensuração inicial de ativos e passivos financeiros deve ser feita pelo valor justo. Quanto a mensuração subsequente, dependerá da classificação dos instrumentos financeiros.

circulante (aumento ou redução), Patrimônio Líquido (aumento ou redução) e Resultado (aumento ou redução).

As diferenças (ou ajustes), decorrentes da adoção inicial das normas internacionais, devem ser reconhecidas diretamente em lucros ou prejuízos acumulados ou, se apropriado, em outra conta do patrimônio líquido, na data de transição.
Patrimônio Líquido (aumento ou redução)

Adoção Inicial
das Normas
Internacionais de Não se aplica
Contabilidade

Fonte: Dados da Pesquisa 